\title{
ANTI-C5A MONOCLONAL ANTIBODY REDUCES CARDIOPULMONARY BYPASS AND CARDIOPLEGIA-INDUCED CORONARY ENDOTHELIAL DYSFUNCTION
}

Motohisa Tofukuji, MD, PhD

Gregory L. Stahl, PhD

Azin Agah, PhD

Caroline Metais, MD

Michael Simons, MD

Frank W. Sellke, MD
Objective: Because C5a induces tissue injury by activating polymorphonuclear leukocytes, the hypothesis was that inhibition of C5a activity would reduce cardioplegia-related injury. Methods: Pigs were placed on cardiopulmonary bypass. The hearts were arrested for 1 hour with hyperkalemic cardioplegia. Pigs were then separated from bypass, and the hearts were reperfused for 2 hours. Anti-porcine C5a monoclonal antibody (1.6 mg/kg, intravenously; $n=6)$ was administered 20 minutes before the onset of cardiopulmonary bypass. Six pigs received saline solution vehicle. Reactivity of coronary arterioles was studied in vitro with videomicroscopy. Microvessels from uninstrumented pigs served as controls for vascular studies. Results: Endothelium-dependent relaxation to adenosine diphosphate (percent relaxation of precontraction) was reduced after cardioplegic reperfusion $(63 \% \pm 14 \%$ vs $77 \% \pm 10 \%$ in control at $10 \mu \mathrm{mol} / \mathrm{L} ; P=.01)$. This impairment in endothelium-dependent relaxation was improved with anti-porcine $C 5$ a monoclonal antibody $(80 \% \pm 22 \% ; P=.01$ vs saline solution), as was the impaired endothelium-dependent relaxation to clonidine $(64 \% \pm 12 \%$ control; $\mathbf{2 6 \%} \pm \mathbf{1 7 \%}$ saline solution; $\mathbf{5 5 \%} \pm \mathbf{2 4 \%}$ anti-porcine $\mathrm{C} 5$ a monoclonal antibody at $10 \mu \mathrm{mol} / \mathrm{L} ; \boldsymbol{P}=.01$ saline solution vs control or anti-porcine C5a monoclonal antibody). Myeloperoxidase activity was significantly decreased $(0.2 \pm 0.2$ units/g protein; $P=.04)$ in the anti-porcine C5a monoclonal antibody group compared with $5.2 \pm 2.7$ in the saline solution group. $\mathrm{CH}_{50} 2$ hours after bypass was not statistically different $(0.57$ \pm 0.41 unit and $0.65 \pm 0.41$ unit, respectively) between the anti-porcine C5a monoclonal antibody and saline solution groups. Despite less myocardial polymorphonuclear leukocyte infiltration after C5a inhibition, maximum rate of rise of left ventricular pressure, percent segmental shortening, and blood flow through the left anterior descending coronary artery were similar in the anti-porcine C5a monoclonal antibody and saline solution groups. Conclusions: Inhibition of C5a limits neutrophil-mediated impairment of endothelium-dependent relaxation after cardiopulmonary bypass and cardioplegic reperfusion, but it has no effect on short-term myocardial functional preservation. ( $J$ Thorac Cardiovasc Surg 1998;116:1060-8)
$\mathrm{C}$ omplement activation, polymorphonuclear leukocytes (PMNs), and increased circulating levels of various cytokines are 3 major causes of tissue damage

From the Division of Cardiothoracic Surgery (M.T., C.M., F.W.S.), Department of Surgery, Cardiovascular Division (M.S.), Department of Medicine, Beth Israel-Deaconess Medical Center, Center for Experimental Therapeutics and Reperfusion Injury, Department of Anesthesiology (G.L.S., A.A.), Brigham and Women's Hospital, and Harvard Medical School, Boston, Mass.

This study was supported by National Institutes of Health grants HL46716, HL53793, HL52886, and HL56086. and endothelial dysfunction after ischemia-reperfusion and cardiopulmonary bypass (CPB). Complement activation as a consequence of exposure of blood compo-

Received for publication April 20, 1998; revisions requested July 16, 1998; revisions received July 28, 1998; accepted for publication Aug 2, 1998.

Address for reprints: Frank W. Sellke, MD, Division of Cardiothoracic Surgery Beth Israel-Deaconess Medical Center, East Campus, Dana 905, 330 Brookline Ave, Boston, MA 02215.

Copyright () 1998 by Mosby, Inc.

0022-5223/98 $\$ 5.00+0 \quad \mathbf{1 2 / 1 / 9 3 6 1 7}$ 
nents to the CPB circuit occurs through both the classical and alternative pathways. ${ }^{1-5}$

The complement fragments C3a, C5a, and C5b-9 all gradually increase in concentration after the initiation of CPB and play a major role in mediating the systemic inflammatory response observed during and after CPB. C5a and C5b-9 may directly activate $\mathrm{PMNs}^{6,7}$ and induce increased expression of the P-selectin and other adhesion molecules on endothelial cell sufaces. ${ }^{8,9}$ Deposition of C5b-9 can be observed on endothelial cells soon after the initiation of reperfusion ${ }^{10}$ and can directly attenuate endothelium-dependent relaxation. ${ }^{11}$ In this regard, Rinder and associates ${ }^{12}$ using an in vitro model, have recently reported that an anti-human C5 monoclonal antibody blocks cleavage of $\mathrm{C} 5$ and effectively attenuates leukocyte activation during CPB. However, specific inhibition of C5a has not been fully tested in a clinically relevant model of CPB and cardioplegia-reperfusion.

In this study, we assessed the efficacy of a monoclonal antibody to C5a in modulating neutrophil chemotaxis and aggregation and complement-mediated hemolysis. Then we used an in vivo porcine model of $\mathrm{CPB}$ and cardioplegia-reperfusion to determine the role of C5a-mediating coronary microvascular endothelial dysfunction, myocardial neutrophil infiltration, systemic complement activation, myocardial edema formation, and possible altered expression of the inducible (iNOS) and constitutive (cNOS) isoforms of nitric oxide synthase.

\section{Methods}

Hybridoma and antibody production/purification. Female Balb-C mice were immunized with $25 \mu \mathrm{g}$ of purified porcine $\mathrm{C} 5 \mathrm{a}$ ( $\mathrm{pC} 5 \mathrm{a}$ ) with standard techniques. Mice received boosters monthly with $25 \mu \mathrm{g}$ of purified pC5a for 3 months. The mice were killed 5 days after intravenous injection of 1 $\mu \mathrm{g}$ of pC5a. Fusion of splenocytes with the P3/NSI/1-Ag4-1 mouse myeloma cell line was done by standard techniques. Hybridomas were screened by an antibody-capture enzymelinked immunosorbent assay (ELISA) with 96-well plates coated with pC5a. Limiting dilution techniques were used to isolate a single positive clone. GS17F1C4 (GS1) was isolated as a murine IgG1k isotype. Antibodies were produced in tissue culture and as ascites. Purification of the antibody was achieved by protein $\mathrm{G}$ column chromatography with glycine (100 mmol/L; pH 3.0) as the elutant.

Porcine PMN purification, chemotaxis, and aggregation studies. Porcine PMN aggregation and chemotaxis studies were performed as we have previously described..$^{13,14}$ Zymosan-activated porcine sera (PAS; $10 \mu \mathrm{L}$ ) was used as the chemotactic agent. GS1 (0 to $51 \mu \mathrm{g} / \mathrm{mL}$ ) was added to the PAS for 30 minutes before application to the chemotaxis wells.
Animal preparation. Yorkshire pigs (20 to $25 \mathrm{~kg}$ ) of either sex were premedicated with ketamine $(10 \mathrm{mg} / \mathrm{kg}$, intramuscularly) and anesthetized with $\alpha$-chloralose and urethane (60 $\mathrm{mg} / \mathrm{kg}$ and $300 \mathrm{mg} / \mathrm{kg}$ intravenously initially and then 15 $\mathrm{mg} / \mathrm{kg}$ and $60 \mathrm{mg} / \mathrm{kg}$ every 60 minutes as needed, respectively). Pigs were intubated and mechanically ventilated (Harvard Apparatus Inc, South Natick, Mass). In the control group $(n=6)$, a sternotomy was performed, and the pigs were heparinized (500 units $/ \mathrm{kg}$ ). The hearts were rapidly excised and immediately placed in a cold $\left(4^{\circ} \mathrm{C}\right.$ to $\left.10^{\circ} \mathrm{C}\right)$ Krebs buffer solution of the following composition (in millimolars): 118.3 $\mathrm{NaCl}, 4.7 \mathrm{KCl}, 2.5 \mathrm{CaCl}_{2}, 1.2 \mathrm{MgSO}_{4}, 1.2 \mathrm{NaH}_{2} \mathrm{PO}_{4}, 25.0$ $\mathrm{NaHCO}_{3}$, and 11.1 glucose.

In 12 pigs, after the induction of anesthesia and tracheal intubation, fluid-filled catheters were introduced into the femoral artery for the measurement of peripheral arterial pressure. After a sternotomy was performed, purse-string sutures were placed in the distal ascending aorta and the right atrium. Instantaneous left anterior descending coronary artery (LAD) blood flow was measured with a $2.5-\mathrm{mm}$ ultrasonic transit-time flow probe (model 2.5S; Transonic System Inc, Ithaca, NY) that was placed around the LAD distal to the second diagonal branch. The flow probe was connected to a flow monitor (model T206; Transonic System Inc). A pair of ultrasonic crystals was implanted 10 to $15 \mathrm{~mm}$ apart and approximately $3 \mathrm{~mm}$ beneath the surface of the left ventricular subepicardium. The crystals were placed parallel to the long axis of the left ventricle. An 8F micromanometer-tipped catheter (model SPC-370; Millar Instruments, Houston, Tex) was placed in the left ventricle through the apex for the measurement of left ventricular systolic pressure (LVSP) and rate of change of $L V$ pressure ( $L V \mathrm{dP} / \mathrm{dt}$ ). $\mathrm{LV} \mathrm{dP/dt}$, the first derivative of LV pressure, was derived by differentiating the left ventricular pressure signal over time. Six pigs were randomized to receive anti-C5a monoclonal antibody (GS1; 1.6 $\mathrm{mg} / \mathrm{kg}$ ) intravenously 20 minutes before the onset of CPB. Six pigs received saline solution vehicle alone. Pigs were given heparin (500 units $/ \mathrm{kg}$ ) and cannulated via the distal ascending aorta and the right atrium through the purse-string sutures. Activated clotting time was maintained for more than 400 seconds. A left ventricular vent was placed via the left ventricular apex for decompression. A small cannula was inserted into the ascending aorta through another purse-string suture for the infusion of cardioplegic solution. Normothermic CPB was instituted with a bubble oxygenator (Bentley Bio-2; Baxter Healthcare Corp, Irvine, Calif) and a standard roller pump. An arterial filter (Bentley Bio-1025; Baxter Healthcare Corp) was inserted into the circuit distal to the roller pump. Blood flow was maintained from 2.0 to 3.0 $\mathrm{L} / \mathrm{min}\left(2.6\right.$ to $\left.4.2 \mathrm{~L} / \mathrm{min} / \mathrm{m}^{2}\right)$ to maintain a mean perfusion pressure of 40 to $70 \mathrm{~mm} \mathrm{Hg}$. Systemic blood temperature was maintained at $37^{\circ} \mathrm{C}$ during the entire study. Arterial blood gases were obtained (model 1306, pH/Blood Gas Analyzer; Instrumentation Laboratory, Lexington, Mass) before CPB was begun and at approximately 15-minute intervals thereafter. Arterial blood gases were adjusted by ventilatory rate and tidal volume to maintain $\mathrm{PaO}_{2}$ more than $50 \mathrm{~mm} \mathrm{Hg}, \mathrm{PCO}_{2}$ 
more than 30 and less than $45 \mathrm{~mm} \mathrm{Hg}$, and $\mathrm{pH}$ between 7.30 and 7.45. After stabilization of the preparation for $\mathrm{CPB}$, an aortic crossclamp was placed and $300 \mathrm{~mL}$ of a cold $\left(0^{\circ} \mathrm{C}\right.$ to $4^{\circ} \mathrm{C}$ ) hyperkalemic crystalloid cardioplegic solution was infused into the aortic root at a pressure of $60 \mathrm{~mm} \mathrm{Hg}$. The composition of hyperkalemic crystalloid cardioplegic solution was (in millimoles per liter): $121 \mathrm{NaCl}, 25 \mathrm{KCl}, 12$ $\mathrm{NaHCO}_{3}, 11.1$ glucose, in purified water. Saline solution slush was placed on the surface of the heart to provide topical hypothermia during the crossclamp period. Myocardial temperature in the distribution of LAD was measured with a probe and ranged from $4^{\circ} \mathrm{C}$ to $10^{\circ} \mathrm{C}$ during the ischemic period. Infusion of the cardioplegic solution $(150 \mathrm{~mL})$ was repeated at 20-minute intervals for 60 minutes ( 2 additional doses). The aortic crossclamp was removed after 60 minutes of cardioplegic arrest, and the heart was reperfused with normothermic blood from the bypass circuit. The heart was kept decompressed with a left ventricular vent until a stable rhythm was obtained. Attempts were made to maintain the mean reperfusion pressure between 40 and $70 \mathrm{~mm} \mathrm{Hg}$. In the event of ventricular fibrillation, lidocaine $(10 \mathrm{mg})$ was infused intravenously, and the heart was defibrillated with $10 \mathrm{~J}$ after the myocardial temperature rose to greater than $30^{\circ} \mathrm{C}$. Pigs were weaned from CPB and decannulated. Heparin was not reversed with protamine. After 120 minutes of reperfusion, the heart was rapidly excised and immediately placed in a cold Krebs buffer solution or in liquid nitrogen.

All animals received humane care in compliance with the Beth Israel Deaconess Medical Center Animal Care and Use Committee and the National Research Council's "Guide for the Care and Use of Laboratory Animals" prepared by the Institute of Laboratory Animals and published by the National Institutes of Health (NIH Publication No. 86-23, revised 1985).

Hemodynamic measurements. The following parameters were measured every 30 minutes: LAD blood flow, mean peripheral arterial pressure (MAP), LVSP, LV maximum $\mathrm{dP} / \mathrm{dt}$ (LV max $\mathrm{dP} / \mathrm{dt}$ ), and percent segmental shortening. Percent segmental shortening was calculated as follows: $100 \times($ enddiastolic segment length-end-systolic segment length)/enddiastolic segment length, where end-diastolic segment length was measured at the onset of $\mathrm{LV} \mathrm{dP} / \mathrm{dt}$ and end-systolic segment length was measured at peak negative $\mathrm{LV} \mathrm{dP} / \mathrm{dt}$.

Measurement of GS1 antibody in porcine plasma. Murine antibody concentrations were measured in porcine plasma collected at various times during the course of the $\mathrm{CPB}$ procedure as described before with modifications. ${ }^{15}$ Briefly, $50 \mu \mathrm{L}$ of a polyclonal antibody to murine $\operatorname{IgG}(2$ $\mu \mathrm{g} / \mathrm{mL}$ in sodium carbonate buffer) was placed in each well of a 96-well microtiter plate and incubated overnight at $4{ }^{\circ} \mathrm{C}$. The plate was washed and blocked with $3 \%$ bovine serum albumin for 2 hours at room temperature. The plates were then washed, covered, and placed at $-20^{\circ} \mathrm{C}$ until used for the ELISA. Known amounts of murine IgG antibody were used to generate a standard curve from $10 \mu \mathrm{g} / \mathrm{mL}$ to $1 \mathrm{ng} / \mathrm{mL}$. Unknown pig plasma samples were diluted 1:40 with Hanks' balanced salt buffer and run in duplicate on the ELISA plates. After the plates were washed, a goat polyclonal anti-murine
IgG antibody conjugated with horseradish peroxidase was added and incubated for 1 hour at room temperature. The plate was washed and then developed with 2,2'azino-bis(3ethylbenzthiol) sulfonic acid and read on a plate reader (Molecular Devices, Sunnyvale, Calif).

Microvascular preparation. Arterial microvessels (60 to $180 \mu \mathrm{m}$, internal diameter) were dissected from the LADdependent subepicardial region in the left ventricle (stored in cold Krebs buffer) with a $\times 10$ to $\times 60$ dissecting microscope (Olympus Optical, Tokyo, Japan) within 6 hours of completion of the animal experiment. Microvessels were placed in a microvessel chamber (University of Iowa Medical Instrumentation, Iowa City, Iowa), cannulated with dual glass micropipettes measuring 40 to $80 \mu \mathrm{m}$ in diameter, and secured with 10-0 nylon monofilament suture (Ethicon, Inc, Somerville, NJ). Oxygenated ( $95 \%$ oxygen $/ 5 \%$ carbon dioxide) Krebs buffer solution warmed to $37^{\circ} \mathrm{C}$ was continuously circulated through the organ chamber. The vessels were pressurized to $40 \mathrm{~mm} \mathrm{Hg}$ in a no-flow state with a burette manometer filled with a Krebs buffer solution. With an inverted microscope $(\times 40$ to $\times 200$, Olympus CK2; Olympus Optical) connected to a video camera, the vessel image was projected onto a black-and-white television monitor. An electronic dimension analyzer (Living System Instrumentation, Burlington, Vt) was used to measure internal lumen diameter. Measurements were recorded (Graphtec, Irvine, Calif). Vessels were allowed to bathe in the organ chamber for at least 30 minutes before an intervention.

Microvessel study protocols. In all experimental groups, relaxation responses of microvessels were examined after precontraction of coronary microvessels with acetylcholine chloride by $20 \%$ to $70 \%$. Once the steady-state tone was reached, the dose responses of the coronary microvessels to adenosine 5'-diphosphate (ADP; receptor-mediated endothelium-dependent vasodilators $10^{-9}$ to $10^{-4} \mathrm{~mol} / \mathrm{L}$ ) and clonidine hydrochloride $\left(\alpha_{2}\right.$-adrenoceptor agonist, $10^{-9}$ to $10^{-5}$ $\mathrm{mol} / \mathrm{L}$ ), and the endothelium-independent vasodilators sodium nitroprusside (endothelium-independent vasodilator, $10^{-9}$ to $10^{-4} \mathrm{~mol} / \mathrm{L}$ ) and isoproterenol ( $\beta$-adrenoceptor agonist, $10^{-12}$ to $10^{-6} \mathrm{~mol} / \mathrm{L}$ ) were examined. Measurements were made and recorded 2 to 3 minutes after the drug was administered, when the response had stabilized. All drugs were applied extraluminally. One to 4 interventions were performed on each vessel. The order of the drug administration was random. The vessels were washed with a Krebs buffer solution and allowed to equilibrate in a drug-free Krebs buffer solution for 15 to 30 minutes between interventions.

Amplification and quantitation of cNOS and iNOS cDNA fragment by reverse transcriptase-polymerase chain reaction. To examine myocardial mRNA of the cNOS and the iNOS, reverse transcriptase-polymerase chain reaction (RT-PCR) was performed. cNOS and iNOS fragments were amplified by RT-PCR from myocardium stored in liquid nitrogen. Primers were designed based on the published $\operatorname{cNOS}^{16}$ and iNOS sequence. ${ }^{17}$ The primers of the sense $5^{\prime}$ AGACCCCTGGAAAGGGAG-3' corresponding to bases 1443-1460 and the antisense 5'-TGTGTTACTGGATTCCTTCC-3' corresponding to bases 1901-1920 were used to 


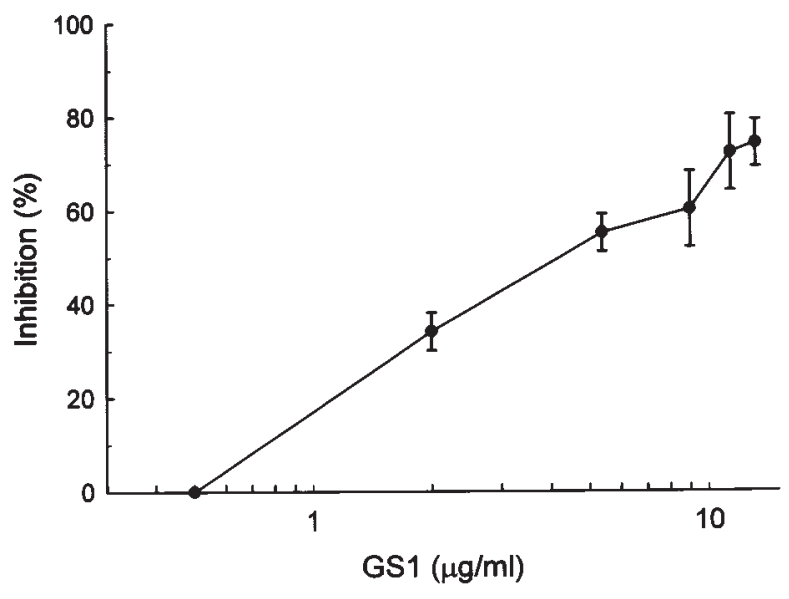

Fig 1. Effect of GS1 on porcine C5a-induced porcine PMN aggregation. GS1 dose dependently attenuated pC5a-induced PMN aggregation. The data represent means \pm SEM of 7 independent experiments.

amplify a 486-base pair fragment of cNOS. ${ }^{16}$ For iNOS, the primer of sense 5'-GCCTCGCTCTGGAAAGA-3' corresponding to bases $1425-1441$ and the antisense $5^{\prime}$-TCCATGCAGACAACCTT-3' corresponding to bases 1908-1924 were used to amplify a 500-base pair fragment of cNOS. ${ }^{17}$ An equal amount of total RNA was used for RT-PCR from control and experimental groups. For quantification, glyceraldehyde-3-phosphate dehydrogenase was amplified from the same amount of RNA to correct for variation of different samples. The PCR products were loaded in $1.5 \%$ agarose gel, scanned, and measured on an Image-Quant software (Molecular Dynamics, Sunnyvale, Calif).

Myocardial myeloperoxidase activity. Tissue samples from the left ventricle were excised at the end of reperfusion, frozen in liquid nitrogen, and stored at $-80^{\circ} \mathrm{C}$ until assayed. Myeloperoxidase activity was measured as Amsterdam and associates ${ }^{18}$ previously described. Ice-cold, minced sections of the tissues were homogenized $(10 \% \mathrm{wt} / \mathrm{vol})$ with a Polytron homogenizer (Brinkmann Instruments, Westbury, NY) in 50 $\mathrm{mmol} / \mathrm{L}$ phosphate buffer solution $(\mathrm{pH} 6.0$ ) containing $0.5 \%$ hexadecyltrimethyl-ammonium bromide for 15 seconds twice. The homogenates were then sonicated for 15 seconds, and the supernatant containing the myeloperoxidase enzyme was separated from the cellular debris by centrifugation at 20,000 $g$ for 15 minutes $\left(2^{\circ} \mathrm{C}\right)$. The appearance of a colored product from the myeloperoxidase-dependent reaction of $o$-dianisidine and hydrogen peroxide $(0.0005 \%)$ was spectrophotometrically detected with $100 \mathrm{~mL}$ of supernatant, $1.9 \mathrm{~mL}$ of hydrogen peroxide, and $o$-dianisidine in $50 \mathrm{mmol} / \mathrm{L}$ phosphate buffer solution $(\mathrm{pH}=6.0)$. Supernatant myeloperoxidase activity was kinetically quantified on a temperature-controlled $\left(25^{\circ} \mathrm{C}\right) \mathrm{spec}-$ trophotometer. The absorbance at $460 \mathrm{~nm}$ was recorded for several minutes, and the change in absorbance over 1 minute was measured during the linear portion ( 0.5 to 1.5 minute) of the tracing. One unit of myeloperoxidase activity was defined as that which degraded $1 \mathrm{~mol}$ hydrogen peroxide/minute at

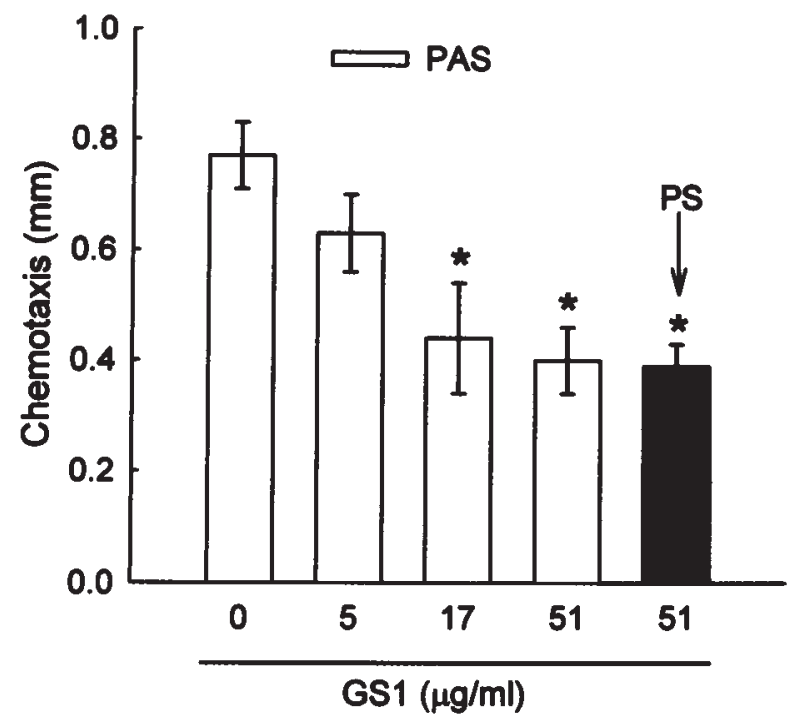

Fig 2. Effect of GS1 on zymosan-activated porcine sera (PAS)-induced chemotaxis of porcine PMN. GS1 dose-dependently attenuated PAS-induced PMN chemotaxis. GS1 (17 $\mathrm{mg} / \mathrm{mL}$ ) significantly inhibited PAS-induced chemotaxis compared with untreated PAS. Chemotaxis induced by normal pig sera $(P S)$ treated with GS1 was not significantly different from PAS treated with GS1 (17 or $51 \mathrm{mg} / \mathrm{mL}$ ). The data represent means \pm SEM of 6 independent experiments. ${ }^{*} P<.05$ vs 0 concentration.

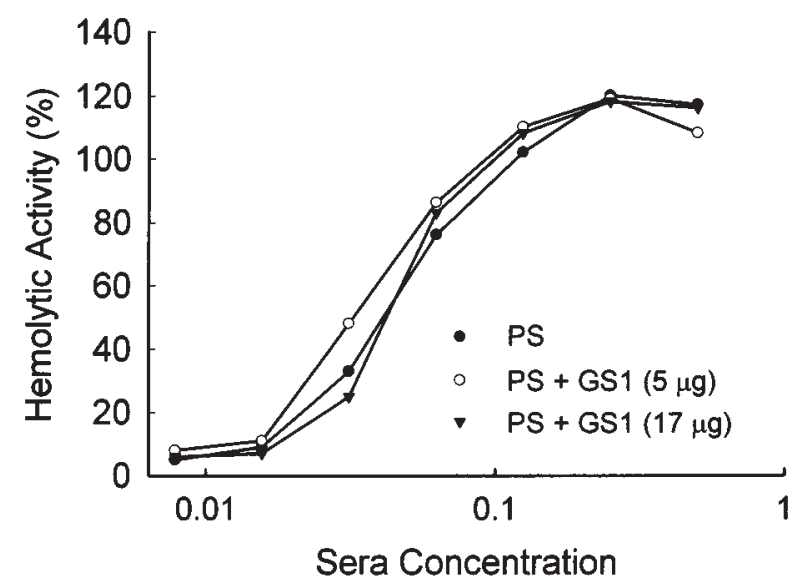

Fig 3. Hemolytic effect of porcine sera on sensitized sheep red blood cells. Porcine sera concentration dependently induced hemolysis of sensitized sheep red blood cells. Treatment of porcine sera with 5 or $17 \mathrm{mg} / \mathrm{mL}$ GS1 did not attenuate porcine sera-induced hemolysis. These data represent the means of 3 separate experiments. No statistically significant differences were observed.

$25^{\circ} \mathrm{C}$. Assessment of this assay with isolated porcine neutrophils demonstrated a linear relationship $(r=0.92)$ between myeloperoxidase and the number of cells, such that 1 unit of myeloperoxidase activity correlated with $2.9 \times 10^{6}$ neutrophils. 


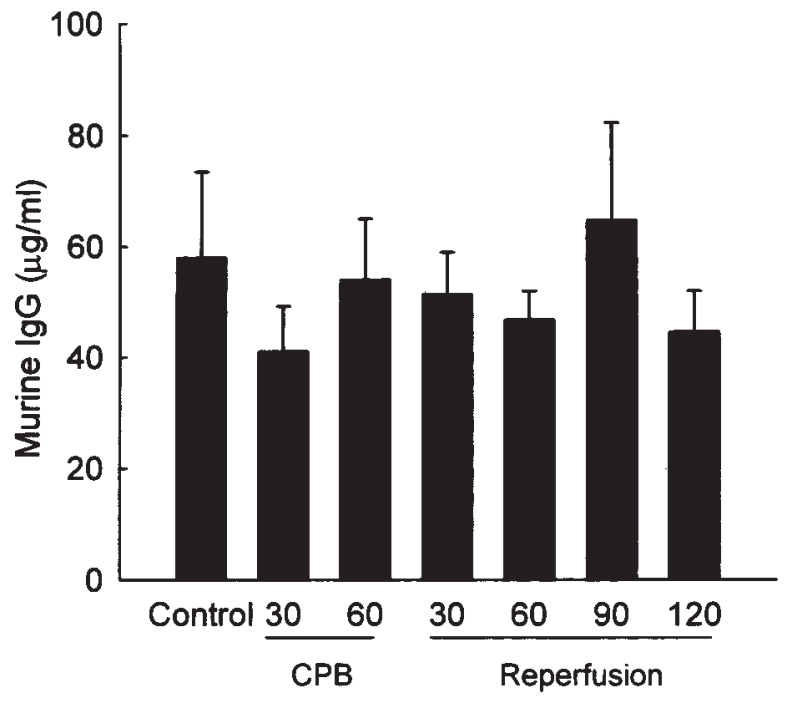

Fig 4. Concentration of GS1 in pig plasma during the course of CPB. GS1 was given at $1.6 \mathrm{mg} / \mathrm{mL}$ just before the control plasma sample was collected. Plasma samples were analyzed by ELISA for murine IgG concentration. GS1 was maintained at greater than $40 \mu \mathrm{g} / \mathrm{mL}$ plasma throughout the experimental protocol. Numbers on the X-axis represent time in minutes during $\mathrm{CPB}$ and perfusion after bypass. Bars and brackets represent means and SEM, respectively. No statistically significant differences were observed.

Porcine sera induced hemolytic assay. Sheep red blood cells were sensitized by standard methods, as described. ${ }^{14}$ Sera dilutions of porcine sera were treated with GS1 (5 or 17 $\mu \mathrm{g} / \mathrm{mL})$.

Percent tissue water. The left ventricular tissues were weighed, incubated at $110^{\circ} \mathrm{C}$ for 12 hours, and then weighed again. Percent tissue water was calculated as follows: (wet weight - dry weight)/wet weight $\times 100$.

Drugs. Isoproterenol, acetylcholine chloride, adenosine 5'diphosphate, and sodium nitroprusside were obtained from Sigma Chemical Company (St Louis, Mo). Clonidine hydrochloride was obtained from Research Biomedicals International (Natick, Mass). All drugs were dissolved in ultrapure distilled water and prepared on the day of the study. Other reagents were obtained from the source listed in the text.

Statistical analysis. Data in the text and tables are presented as mean $\pm \mathrm{SD}$. The relaxation responses in the figures are expressed as the percent relaxation of the acetylcholine precontracted diameter (mean \pm SEM) of the microvessels. Comparisons of dose-response curves of all experimental groups were performed by 2-way analysis of variance with repeated measure design followed by Scheffe's multiple comparison test when indicated. Comparison of hemodynamic variables, myeloperoxidase activities, myocardial wet/dry ratios, and gene expressions were compared with 1-way ANOVA and Scheffe's test post hoc with Statview 4.02
(Abacus Concepts, Inc, Berkeley, Calif). PMN GS1 antibody effects were compared with 1-way ANOVA and NeumanKeuls test post hoc with Sigma Stat 2.0 (Jandel Scientific Software, SPSS, Inc, Chicago, Ill).

\section{Results}

Anti-C5a antibody. The monoclonal antibody, GS1, is a murine $\mathrm{IgG}_{1 \mathrm{k}}$ isotype. GS1 bound to purified pC5a was assessed by ELISA. pC5a (100 ng/mL) -induced porcine neutrophil (PMN) aggregation was significantly inhibited by $10 \mathrm{mg} / \mathrm{mL}$ GS1 $(58 \% \pm 15 \%$ vs $15 \% \pm$ $7 \%$, respectively). GS1 inhibited pC5a (100 ng/ml) induced porcine $\mathrm{PMN}$ aggregation with an $\mathrm{IC}_{50}$ of approximately $3 \mathrm{mg} / \mathrm{mL}$. PAS-induced chemotaxis of porcine PMN was concentration-dependent inhibited by GS1. PAS-induced chemotaxis was significantly $(P$ $=.02$ ) inhibited by $17 \mathrm{mg} / \mathrm{mL}$ GS1 compared to untreated PAS $(0.44 \pm 0.24 \mathrm{~mm}$ vs $0.77 \pm 0.15 \mathrm{~mm}$, respectively). GS1 (17 $\mathrm{mg} / \mathrm{mL})$ failed to inhibit porcine sera-induced hemolytic activity with sensitized sheep red blood cells (Figs 1, 2, and 3). Plasma concentration of GS1 during the experimental protocol was greater than $40 \mu \mathrm{g} / \mathrm{mL}$ plasma (Fig 4).

Hemodynamic parameters. Although MAP, LVSP, $\mathrm{LV} \max \mathrm{dP} / \mathrm{dt}$, and percent segmental shortening were significantly decreased $(P=.01$ vs baseline for all variables) at the end of reperfusion, there was no significant difference between the groups for any of the variables (Table I). LAD blood flow was increased after reperfusion because of the hyperemic response and was similar between the groups.

Microvessel characteristics. Coronary microvessels ranged between 60 and $178 \mu \mathrm{m}$ in internal diameter, averaging $120 \pm 9 \mu \mathrm{m}$ in the control group and $120 \pm 17$ $\mu \mathrm{m}$ and $126 \pm 14 \mu \mathrm{m}$ in the saline solution and GS1 groups, respectively. Percent precontraction after the application of acetylcholine was $50 \% \pm 10 \%$ in the control group, and $60 \% \pm 10 \%$ and $57 \% \pm 17 \%$ in the saline solution and GS1 groups, respectively. Mean concentrations of acetylcholine required to obtain these percent contractions were $1.5 \pm 0.7 \times 10^{-7}$ in the control group and $1.8 \pm 1.0 \times 10^{-7}$ and $1.4 \pm 0.7 \times 10^{-7} \mathrm{~mol} / \mathrm{L}$ in the saline solution and GS1 groups, respectively.

Endothelium-dependent relaxation. Relaxation responses to the receptor-mediated endotheliumdependent vasodilator ADP were significantly reduced in the saline solution group ( $P=.01$ vs control; Fig 5). The responses to ADP were preserved in the GS1 group ( $P=.01$ vs saline solution group). Similarly, relaxation responses to the $\alpha_{2}$-adrenoceptor agonist and endothelium-dependent vasodilator clonidine were significantly reduced after cardioplegia-reperfusion $(P$ 


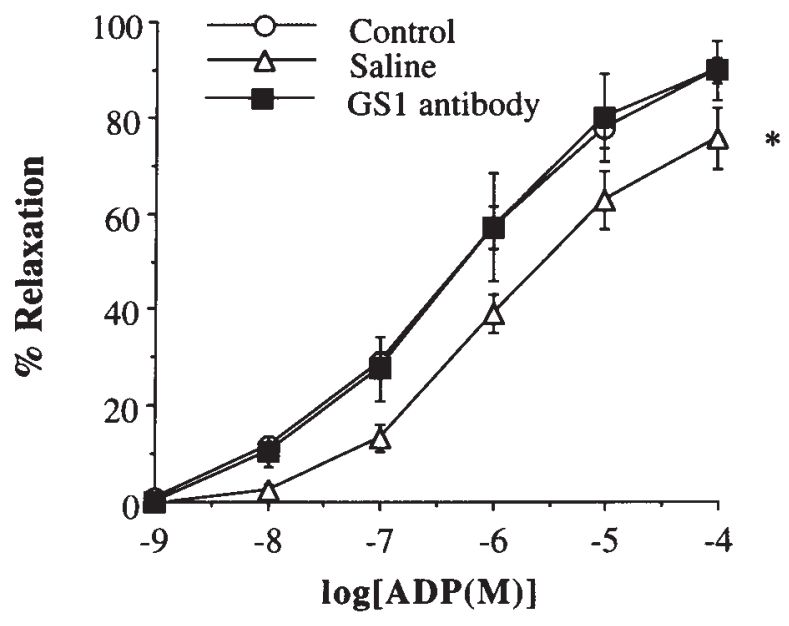

Fig 5. In vitro responses of precontracted porcine coronary microvessels to ADP from control (uninstrumented) hearts and hearts in the saline solution and GS1 groups. Responses are expressed as percent relaxation of acetylcholine-induced precontraction. ${ }^{*} P=.01$ versus control and GS1 groups; mean \pm SEM.

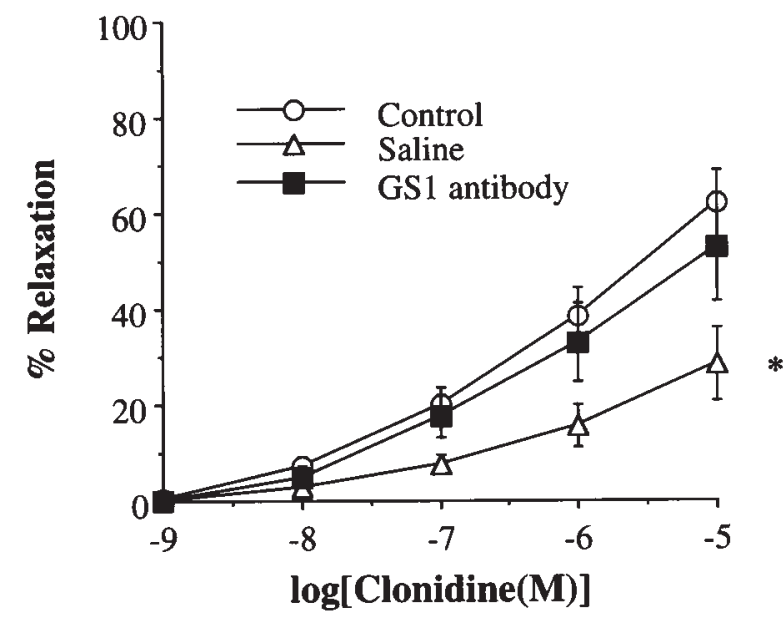

Fig 6. In vitro responses of precontracted porcine coronary microvessels to clonidine from control (uninstrumented) hearts and hearts in the saline solution and GS1 groups. Responses are expressed as percent relaxation of acetylcholine-induced precontraction. $* P=.01$ versus control and GS1 groups; mean \pm SEM.

Table I. Hemodynamics before and after CPB and cardioplegia-reperfusion

\begin{tabular}{|c|c|c|c|c|c|c|c|c|}
\hline & \multicolumn{4}{|c|}{ Saline solution } & \multicolumn{4}{|c|}{ GS1 antibody } \\
\hline & Baseline & $\begin{array}{c}\text { 30-Min } \\
C P B\end{array}$ & $\begin{array}{l}\text { 60-Min } \\
\text { reperfusion }\end{array}$ & $\begin{array}{l}\text { 120-Min } \\
\text { reperfusion }\end{array}$ & Baseline & $\begin{array}{c}\text { 30-Min } \\
C P B\end{array}$ & $\begin{array}{l}\text { 60-Min } \\
\text { reperfusion }\end{array}$ & $\begin{array}{l}\text { 120-Min } \\
\text { reperfusion }\end{array}$ \\
\hline MAP (mm Hg) & $82 \pm 16$ & $49 \pm 10^{*}$ & $44 \pm 15^{*}$ & $40 \pm 14^{*}$ & $85 \pm 15$ & $52 \pm 7 *$ & $45 \pm 9^{*}$ & $42 \pm 6^{*}$ \\
\hline LVSP (mm Hg) & $107 \pm 27$ & - & $77 \pm 16^{*}$ & $58 \pm 6^{*}$ & $112 \pm 4$ & - & $74 \pm 18^{*}$ & $54 \pm 17 *$ \\
\hline LV max dP/dt (mm Hg/sec) & $1280 \pm 360$ & - & $1310 \pm 566$ & $910 \pm 160^{*}$ & $1320 \pm 230$ & - & $1420 \pm 414$ & $910 \pm 240$ \\
\hline Percent segmental shortening & 100 & - & $20.6 \pm 20.1^{*}$ & $20.4 \pm 16.2^{*}$ & 100 & - & $28.0 \pm 29 *$ & $23.2 \pm 22.7 *$ \\
\hline LAD flow (mL/min) & $15 \pm 5$ & - & $31 \pm 13^{*}$ & $21 \pm 8$ & $17 \pm 5$ & - & $30 \pm 11^{*}$ & $25 \pm 9$ \\
\hline
\end{tabular}

Data are mean \pm SD.

$* P=.01$ versus baseline.

$=.01$ vs control; Fig 6). Relaxation to clonidine was preserved in pigs treated with the GS1 antibody.

Endothelium-independent relaxation. Relaxation responses to sodium nitroprusside were similar in all groups, indicating no alteration in the ability of the vascular smooth muscle to relax through the cyclic guanosine monophosphate (Fig 7).

$\beta$-Adrenoceptor-mediated relaxation. Isoproterenol induced a significant relaxation in the control microvessels. The relaxation response to isoproterenol in the saline solution and GS1 groups were unchanged compared with the responses of vessels from the control group (Fig 8).

Myocardial myeloperoxidase activity. Myeloperoxidase activity was $0.2 \pm 0.2$ units/g protein in the control group, and $5.2 \pm 2.7$ units/g protein $(P=.04$ vs control) and $0.2 \pm 0.2$ units/g protein, $(P=.04$ vs saline solution) in the saline solution and GS1 groups, respectively. This suggests a significant inhibition by GS1 of C5a-induced neutrophil infiltration in the myocardium after cardioplegia-reperfusion.

cNOS and iNOS expression. The expressions of cNOS in the saline solution group $(0.32 \pm 0.13$, cNOS signal density/glyceraldehyde-3-phosphate dehydrogenase density; $P>.2)$ or the GS1 group $(0.58 \pm 0.68, P$ $>$.2) were unchanged in the myocardium after cardioplegia and reperfusion compared with that in control myocardial specimens $(0.21 \pm 0.16)$. However, iNOS expression was increased 2-fold after cardioplegia and 2 hours of reperfusion in the saline solution group (1.03 $\pm 0.50 ; P=.03)$ compared with that in the control myocardium $(0.41 \pm 0.17)$. The increased expression of 


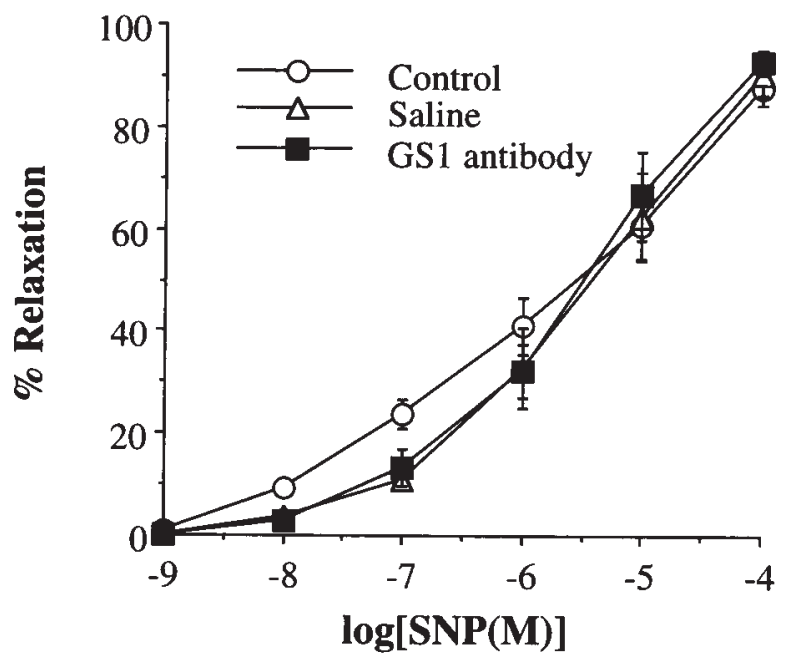

Fig 7. In vitro responses of precontracted porcine coronary microvessels to sodium nitroprusside $(S N P)$ from control (uninstrumented) hearts and hearts in the saline solution and GS1 groups. Responses are expressed as percent relaxation of acetylcholine-induced precontraction; mean \pm SEM.

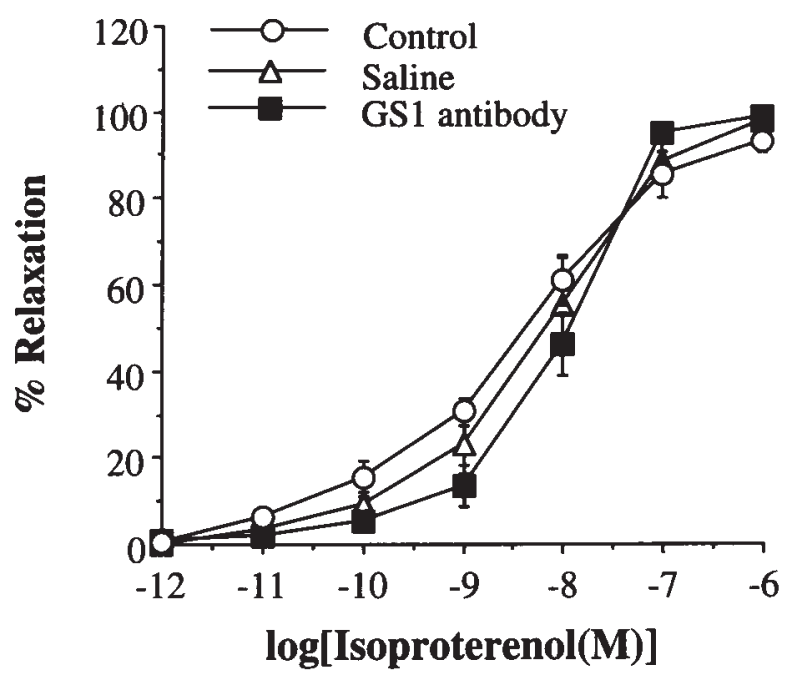

Fig 8. In vitro responses of precontracted porcine coronary microvessels to isoproterenol from control (uninstrumented) hearts and hearts in the saline solution and GS1 groups. Responses are expressed as percent relaxation of acetylcholine-induced precontraction; mean \pm SEM.

iNOS in the GS1 group $(0.93 \pm 0.91 ; P>.2$ vs control $)$ was not statistically significant. There was no effect of GS1 antibody on the expression of either isoform of NOS. Representative blots are shown in Fig 9.

Total hemolytic complement activity $\mathbf{C H}_{\mathbf{5 0}}$. The $\mathrm{CH}_{50}$ was $0.16 \pm 0.15$ (concentration of sera $^{-1}$ ) before $\mathrm{CPB}$ and $0.57 \pm 0.33$ after 2 hours of perfusion after

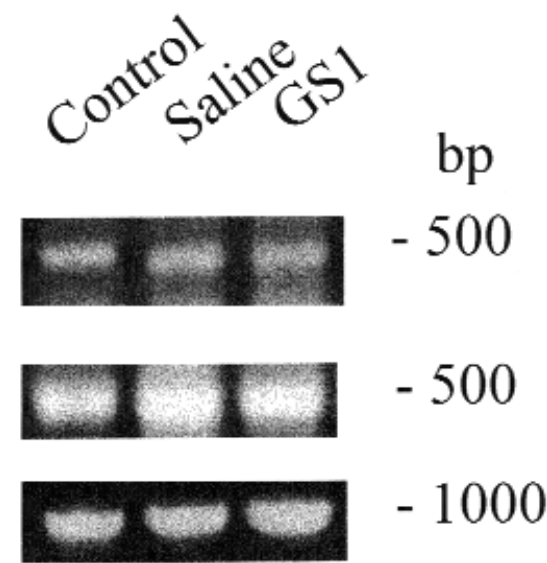

Fig 9. Representative RT-PCR products of cNOS, iNOS in porcine myocardium, shown in glyceraldehyde-3-phosphate dehydrogenase-stained $(G A P D H) 1.5 \%$ agarose gel for amount of RNA control. Control (uninstrumented); saline solution-treated group; GS1 antibody-treated group.

CPB ( $P=.04$ vs before $\mathrm{CPB})$ in the GS1 group, compared with $0.65 \pm 0.36(P=.03$ vs before $\mathrm{CPB})$ in the saline solution group. There was no significant difference between the saline solution and GS1 groups at 2 hours after CPB.

Wet/dry ratio. Myocardial wet/dry ratio was $4.21 \pm$ 0.17 in the control group, and $4.68 \pm 0.34(P=.03 \mathrm{vs}$ control) and $4.69 \pm 0.24(P=.03$ vs control $)$ in the saline solution and GS1 groups, respectively. Although a significant increase in myocardial water was noted between the control and saline solution groups, GS1 did not reduce the ratio.

\section{Discussion}

The new findings of this study are that functional and selective inhibition of C5a limits PMN-mediated impairment of endothelium-dependent relaxation after $\mathrm{CPB}$ and cardioplegia-reperfusion. This is likely due to reduced neutrophil chemotaxis but not due to the inhibition of complement activation. Despite improved endothelial functional preservation, inhibition of C5ainduced PMN infiltration had no effect on myocardial functional preservation, increased expression of iNOS, or formation of myocardial edema after 2 hours of reperfusion after cardioplegia. Previous studies have implicated a role of C5a in mediating some of the myocardial ischemia-reperfusion injury in pigs and other animals. ${ }^{13-15,18,19}$ However, pure ischemia and ischemia under conditions of myocardial protection and CPB may produce different cellular and biochemical injury. It is known the complement activation is involved in alterations of vascular and myocardial 
function after ischemia or CPB..$^{5,10,14,20}$ The terminal membrane attack complex C5b-9 has a direct cytolytic action, ${ }^{11,21}$ whereas the complement anaphylatoxin $\mathrm{C} 5 \mathrm{a}$ has indirect actions including increased PMN activation, chemotaxis, aggregation, and vascular plugging. ${ }^{22,23}$ This may, in theory, lead to increased vascular permeability and altered endothelial function.

Endothelium-dependent relaxation of coronary microvessels to ADP and clonidine was significantly improved with C5a inhibition in this model of cardioplegia-reperfusion. The associated reduction of myeloperoxidase activity suggests that the reduced PMN chemotaxis and adhesion leads to the benefical effect on vasomotor regulation and NOS activity. Because complement activation was not inhibited by the administration of GS1 (no change in $\mathrm{CH}_{50}$ ), the cytolytic and other actions of the C5b-9 terminal membrane attack complex may not be the only causes of endothelial dysfunction after CPB and cardioplegia, although C5b-9 certainly plays a role. During myocardial ischemia, subcellular membrane fragments activate the complement cascade ${ }^{24}$ that play an important role in mediating reperfusion injury. Immediately after the onset of myocardial reperfusion, the alternative complement pathway is activated. ${ }^{18}$ Unlike pure myocardial ischemia or cardioplegia, CPB itself activates the alternate complement pathway. In addition, the formation of the protamine-heparin complex formation shortly after administration of protamine potently activates the classic complement pathway. ${ }^{25}$ Thus multiple factors lead to activation of the complement cascades during $\mathrm{CPB}$ and cardioplegia, including tissue ischemia, contact of blood with foreign surfaces, and pharmacologic agents. Surprisingly, myocardial function after reperfusion in our study was not improved with administration of the GS1, as has been reported in a myocardial infarction model using a similar monoclonal antibody to C5a. ${ }^{18}$ This may be due to a difference between our clinically applicable model of cardioplegia and other models of ischemia-reperfusion that do not include CPB or cardioplegia. On the other hand, these findings may suggest that the endothelium of the coronary microvasculature is more sensitive to the effects of C5a than is myocardial contractile function. However, it is also possible that a longer duration of cardioplegia or reperfusion may have brought out a beneficial functional effect of $\mathrm{C} 5 \mathrm{a}$ inhibition. One potential criticism of the study is that the GS1 antibody may not have been effective in inhibiting the effects of C5a. However, the concentration of the GS1 used in the study clearly was sufficient to inhibit the effects of C5a on PMN chemotaxis and aggregation. Furthermore, GS1 reduced neutrophil infiltation in the myocardium and improved endothelial function. Thus lack of efficacy of the antibody was ruled out as a cause for the failure of GS1 to improve myocardial recovery after cardioplegia.

Because improvement of myocardial contractile function after reperfusion was not observed, selective inhibition of C5a did improve the impaired endothelium-dependent relaxation via release of nitric oxide from the microvascular endothelium that has been reported previously. ${ }^{26}$ One factor potentially contributing to this may be an alteration in the expression of cNOS, through which ADP and clonidine cause the release of nitric oxide. Increased concentration of circulating cytokines during CPB and cardioplegia may lead to an increased expression of iNOS, which has been implicated in causing cellular injury through direct actions or indirectly via formation of the peroxynitrite free radical. In this study, expression of iNOS was slightly increased after 1 hour of cardioplegia and 2 hours of reperfusion. It is probable that prolonged reperfusion would lead to greater iNOS expression because the altered expression of the iNOS gene has been reported to require 4 or more hours in many studies. On the other hand, the expression of cNOS was not altered after cardioplegia, nor was the cNOS expression affected by the GS1 antibody. Thus altered expression of either isoform of NOS did not contribute to improvement in endothelium-dependent relaxation or to the reduced infiltration of PMNs in the myocardium as a result of GS1 administration.

In summary, a selective inhibition of complement fragment C5a limits PMN-mediated impairment of endothelium-dependent relaxation after CPB and cardioplegia-reperfusion. Therefore the modulation of complement has the potential to improve the recovery of patients after cardiac operation, because of decreased vascular permeability, improved vasomotor regulation, and maintenance of the activity of NOS and other homeostatic mechanisms. ${ }^{27}$ However, despite clear inhibition of myocardial PMN infiltration and preservation of endothelial function, GS1 had no effect on short-term myocardial functional improvement.

We thank Jennifer M. Lee, Alvin Franklin, Dr. Jianyi Li, and Dr. Mukesh D. Hariawala for their technical assistance and Dr. Kalon Ho for the statistical review.

\section{REFERENCES}

1. Wachtfogel YT, Harpel PC, Edmunds LH Jr, Colman RW. Formation of $\mathrm{C}_{\mathrm{s}}-\mathrm{C}_{1}$-inhibitor, kallikrein- $\mathrm{C}_{1}$-inhibitor, and plasmin- $\alpha_{2}$-plasmin-inhibitor complexes during cardiopulmonary bypass. Blood 1989;73:468-71.

2. Steinberg JB, Kapelanski DP, Olson JD, Weiler JM. Cytokines 
and complement levels in patients undergoing cardiopulmonary bypass. J Thorac Cardiovasc Surg 1993;106:1008-16.

3. Kalfin RE, Engelman RM, Rousou JA, et al. Induction of interleukin-8 expression during cardiopulmonary bypass. Circulation 1993;88(Suppl):II401-6.

4. Butler J, Rocker GM, Westaby S. Inflammatory response to cardiopulmonary bypass. Ann Thorac Surg 1993;55:552-9.

5. Gillinov AM, Redmond JM, Winkelstein JA, et al. Complement and neutrophil activation during cardiopulmonary bypass: a study in the complement-deficient dog. Ann Thorac Surg 1994;57:34552.

6. Tonnesen MG, Anderson DC, Springer TA, Knedler A, Avdi N, Henson PM. Adherence of neutrophils to cultured human microvascular endothelial cells: stimulation by chemotactic peptides and lipid mediators and dependence upon the Mac-1, LFA1, p150,95 glycoprotein family. J Clin Invest 1989;83:637-46.

7. Fletcher MP, Stahl GL, Longhurst JC. C5a-induced myocardial ischemia: role for CD18-dependent PMN localization and PMNplatelet interactions. Am J Physiol 1993;265:H1750-61.

8. Hattori R, Hamilton KK, Fugate RD, McEver RP, Sims PJ. Complement proteins C5b-9 induce secretion of high molecular weight multimers of endothelial von Willebrand factor and translocation of granule membrane protein GMP-140 to the cell surface. J Biol Chem 1989;264:9053-60.

9. Foreman KE, Vaporciyan AA, Bonish BK, et al. C5a-induced expression of P-selectin in endothelial cells. J Clin Invest 1994; 94:1147-55.

10. Weisman HF, Bartow T, Leppo MK, et al. Soluble human complement receptor type 1: in vivo inhibitor of complement suppressing post-ischemic myocardial inflammation and necrosis. Science 1990;249:146-51.

11. Stahl GL, Reemstra WR, Frendl G. Complement-mediated loss of endothelium-dependent relaxation of porcine coronary arteries: role of the terminal membrane attack complex. Circ Res 1995;76:575-83.

12. Rinder CS, Rinder HM, Smith BR, et al. Blockade of C5a and C5b-9 generation inhibits leukocyte and platelet activation during extracorporeal circulation. J Clin Invest 1995;96:1564-72.

13. Stahl GL, Fletcher MP, Amsterdam EA, Longhurst JC. Role of granulocytes and C5a in myocardial response to zymosan-activated serum. Am J Physiol 1991;261:H29-37.

14. Vakeva A, Agah A, Rollins SA, Matis LA, Li L, Stahl GL. Myocardial infarction and apoptosis after myocardial ischemia and reperfusion: role of the terminal complement components and inhibition by anti-C5 therapy. Circulation 1998;97:2259-67.

15. Amsterdam EA, Stahl GL, Pan H-L, Rendig SV, Fletcher MP, Longhurst JC. Limitation of reperfusion injury by a monoclonal antibody to $\mathrm{C} 5 \mathrm{a}$ during myocardial infarction in pigs. Am J Physiol 1995;268:H448-57.

16. Zhang JL, Patel JM, Block ER. Molecular cloning, characterization and expression of a nitric oxide form porcine pulmonary artery endothelial cells. Comp Biochem Physiol B Mol Biol 1997; 116:485-91.

17. Geller DA, Lowenstein CJ, Shapiro RA, et al. Molecular cloning and expression of inducible nitric oxide synthase from human hepatocytes. Proc Natl Acad Sci U S A 1993;90:3491-5.

18. Amsterdam EA, Stahl GL, Pan HL, Rendig SV, Fletcher MP, Longhurst JC. Limitation of reperfusion injury by a monoclonal antibody to C5a during myocardial infarction in pigs. Am J Physiol 1995;268:H448-57.

19. Martin SE, Chenoweth DE, Engler RL, Roth DM, Longhurst JC. C5a decreases regional coronary blood flow and myocardial function in pigs: implications for a granulocyte mechanism. Circ Res 1988;63:483-91.

20. Finn A, Morgan BP, Rebuck N, et al. Effect of inhibition of complement activation using recombinant soluble receptor 1 on neutrophil CD11b/CD18 and L-selectin expression and release of interleukin- 8 and elastase in simulated cardiopulmonary bypass. J Thorac Cardiovasc Surg 1996;111:451-9.

21. Homeister JW, Satoh P, Lucchesi BR. Effects of complement activation in the isolated heart: role of the terminal complement components. Circ Res 1992;71:303-19.

22. Crawford MH, Grover FL, Kolb WP, et al. Complement and neutrophil activation in the pathogenesis of ischemic myocardial injury. Circulation 1988;78:1449-58.

23. Stahl GL, Amsterdam EA, Symons JD, Longhurst JC. Role of thromboxane $\mathrm{A}_{2}$ in the cardiovascular response to intracoronary C5a. Circ Res 1990;66:1103-11.

24. Rossen RD, Michael LH, Kagiyama A, et al. Mechanism of complement activation after coronary artery occlusion: evidence that myocardial ischemia in dogs causes release of constituents of myocardial subcellular origin that complex with human C1q in vivo. Circ Res 1988;62:572-84.

25. Kirklin JK, Chenoweth DE, Naftel DC, et al. Effects of protamine administration after cardiopulmonary bypass on complement, blood elements, and the hemodynamic state. Ann Thorac Surg 1986;41:193-9.

26. Sellke FW, Shafique T, Schoen FJ, Weintraub RM. Impaired endothelium-dependent coronary microvascular relaxation after cold potassium cardioplegia and reperfusion. J Thorac Cardiovasc Surg 1993;105:52-8.

27. Sellke FW, Boyle EM, Verrier ED. Endothelial cell injury in cardiovascular surgery: the pathophysiology of vasomotor dysfunction. Ann Thorac Surg 1996;62:1222-8. 